\title{
Intraseasonal (30-60 day) variability in the global tropics: principal modes and their evolution
}

By M. T. KAYANO ${ }^{1 *}$ and V. E. KOUSKY ${ }^{2},{ }^{1}$ Instituto Nacional de Pesquisas Espaciais, Avenida dos Astronautas 1758, 12227-010 São José dos Campos, SP, Brazil and ${ }^{2}$ Climate Prediction Center of the National Centers for Environmental Prediction, 5200 Auth Road, Camp Springs, MD 20746, USA

(Manuscript received 28 July 1998; in final form 21 January 1999)

\begin{abstract}
The evolution of the 30-60 day intraseasonal (Madden-Julian) oscillation (MJO), during boreal winter and summer, is studied by means of extended empirical orthogonal function analyses. For both seasons, the patterns describe an eastward traveling large-scale oscillatory regime with a period of approximately 45 days. Several atmospheric variables display a zonal wavenumber one pattern approximately symmetric about the equator. The seasonal variation of the MJO is investigated, especially in terms of the intraseasonal variability of the tropical convection. We find that the latitudinal location of the largest outgoing longwave radiation anomalies is directly related to the seasonal meridional shifts of the tropical convection in the Indo-Australian and Central American-South American regions. In the eastern hemisphere, the MJO affects the monsoons over India during boreal summer and over Australia during austral summer. In the western hemisphere the MJO has the greatest impact on convection over Northeast Brazil during austral summer and over Central America during boreal summer. The MJO-related evolution of $925-\mathrm{hPa}$ specific humidity patterns (not previously documented) show remarkable seasonal dependence. The boreal summer patterns contain a large-scale component quite similar to that shown in the sea level pressure patterns. The austral summer patterns show strong regional variability that might indicate the interactions of the MJO with deep tropical convection in certain areas, such as along the South Pacific Convergence Zone and over northern South America.
\end{abstract}

\section{Introduction}

Low-frequency variability in the tropics is dominated by interannual variations associated with the Southern Oscillation (Rasmusson and Arkin, 1985) and by intraseasonal variations associated with the Madden-Julian Oscillation (MJO) (Madden and Julian, 1971, 1972, 1994; Weickmann, 1983; Weickmann et al., 1985; Lau and Chan, 1985; Knutson et al., 1986; Knutson and Weickmann, 1987; Kiladis and Weickmann, 1992). Both of these phenomena feature nearglobal patterns of anomalous atmospheric circula-

* Corresponding author. tion that are closely related to variations in precipitation in many regions of the tropics and subtropics. The MJO displays variability on the intraseasonal time scale, with periods of 30-60 days (Madden and Julian, 1971, 1972, 1994). Thus, the MJO can have a significant impact on regions that experience relatively short rainy seasons, such as northeast Brazil, southeast Africa, and northeast Australia.

The MJO features an eastward propagating large-scale direct zonal circulation cell in the equatorial plane (Madden and Julian, 1972, 1994). A manifestation of this feature is an eastward propagation of outgoing longwave radiation (OLR) anomalies, which are relatively strong over 
the warm water regions of the Indian and western Pacific Oceans, inconspicuous over the cool waters in the eastern Pacific, and weak but detectable over South America and Africa (Weickmann, 1983; Weickmann et al., 1985; Knutson et al., 1986; Knutson and Weickmann, 1987; Kiladis and Weickmann, 1992; Kousky and Kayano, 1994).

A distinct pattern of low- and upper-level tropical atmospheric circulation anomalies accompanies the eastward shift of anomalous convective activity (Madden and Julian, 1972; Weickmann, 1983; Weickmann et al., 1985). By using upperand lower-tropospheric velocity potential anomalies a continuous eastward propagation of the MJO can be seen throughout the tropics (Knutson and Weickmann, 1987). The shifts in the pattern of tropical convection have also been linked to variations in extratropical atmospheric circulation, particularly in the region of the Pacific Ocean and the Americas (Weickmann, 1983; Lau and Chan, 1985; Weickmann et al., 1985; Madden, 1986; Knutson and Weickmann, 1987; Ghil and Mo, 1991; Kiladis and Weickmann, 1992; Mo and Kousky, 1993; Higgins and Mo, 1997).

Madden and Julian (1994) pointed out another aspect of the MJO, that is its zonal-mean (wavenumber zero) structure depicted in several variables. An illustration for sea level pressure (SLP) can be seen in the dominant intraseasonal pattern determined by Kousky and Kayano (1993). Anderson and Stevens (1987), using a zonally symmetric model, studied the zonal-mean modes and suggested that the MJO may result from a combination of the zonally symmetric modes and the asymmetric traveling modes. The zonal-mean structure of the MJO is associated with variations in the Earth's angular momentum, which result in variations in the rotation rate of the Earth or the length of day (Langley et al., 1981; Anderson and Rosen, 1983). Corresponding fluctuations in the atmospheric angular momentum have also been observed (Langley et al., 1981; Rosen and Salstein, 1983; Madden, 1987).

The purpose of this paper is to further investigate the MJO-related large-scale spatial structures for several variables using the NCEP/NCAR Reanalysis data (Kalnay et al., 1996). The data for the period from January 1979 to December 1995 are used in this paper. Our study focuses on determining the evolution of the principal MJO modes for winter and summer. Since the MJO plays an important role in modulating the globalscale tropical and subtropical patterns of rainfall and atmospheric circulation with periods from 30 to 60 days, enhancing our knowledge on several aspects of the phenomenon is of intrinsic interest in improving climate monitoring. Improved realtime monitoring of this phenomenon can potentially lead to improved forecasts with lead times of 1 to 6 weeks.

\section{Data and methodology}

The dataset used in this study consists of nonoverlapping five-day (pentad) means for selected atmospheric variables derived from the reanalyzed fields produced by the Climate Data Assimilation System (CDAS)/Reanalysis Project (Kalnay et al., 1996). Pentad-means for the 1979-1995 period are computed for $200-$ and $850-\mathrm{hPa}$ zonal winds, $200-\mathrm{hPa}$ velocity potential, $500-\mathrm{hPa}$ geopotential height and pressure vertical velocity, 925-hPa temperature and specific humidity, SLP and total precipitable water $(\mathrm{PW})$. As a proxy for deep tropical convection we use pentad OLR data (Gruber and Krueger, 1984), derived from measurements made by the NOAA operational polarorbiting satellites for the 1979-1995 period. Pentad anomalies are computed as departures from the 1979-1995 base period means. The reanalyzed atmospheric and OLR data have a resolution of $2.5^{\circ}$ in latitude and longitude. The data are temporally filtered using a Lanczos band-pass filter (Duchon, 1979) with 97 weights and cutoff frequencies of 0.2 pentad $^{-1}$ and 0.0575 pentad $^{-1}$, which correspond to periods of 25 and 87 days, respectively. This filter is described by Kousky and Kayano (1994).

The extended empirical orthogonal functions (EEOFs) (Weare and Nasstrom, 1982) are determined for $200-\mathrm{hPa}$ velocity potential in the zonally global domain between $40^{\circ} \mathrm{N}$ and $40^{\circ} \mathrm{S}$, where the filtered anomaly time series for this variable have been sampled on a $10^{\circ}$ in latitude and longitude resolution staggered grid. The spatial patterns for this variable are extended to include patterns at 10 different times (lags) with a interval of one pentad. Spatial patterns for each mode for all variables are obtained at a resolution of $5^{\circ}$ in latitude and longitude by linearly correlating the respective amplitude time series of the $200-\mathrm{hPa}$ 
velocity potential EEOFs with the filtered anomaly time series for each variable at every grid point. The spatial patterns for each variable are also extended to include 10 different times (lags). This method is similar to that proposed by Wallace et al. (1990) to obtain empirical orthogonal function (EOF) patterns for several variables, except that it is applied to determine EEOF patterns for several variables. It has the advantages of reducing the computational time and space and preserving the physical consistency among the variables.

Since velocity potential anomalies at upper- and lower-tropospheric levels show a continuous eastward propagation of the MJO throughout the tropics (Knutson and Weickmann, 1987), we have chosen $200-\mathrm{hPa}$ velocity potential to perform the EEOF analysis. The EEOF calculations are based on the correlation matrix and performed separately for the boreal summer (May to September) and winter (November to March) seasons. In our discussions we will assume a positive amplitude for the modes, so that for each variable the sign of the correlations corresponds with the sign of the anomalies.

To assess the statistical significance of the correlations, we estimated the number of degrees of freedom using the method of Zhang and Hendon (1997). The result is 37 degrees of freedom, which is the total number of pentads in a time series, 450 ( 15 years times 30 pentads for a season), divided by 12 (the number of pentads for a 60 -day period). Using the Student's $t$-test, it is found that absolute correlations $>0.27$ are significant at the $90 \%$ confidence level. Thus, only correlations greater than 0.3 or less than -0.3 are considered in our analysis.

\section{Results}

For both seasons, the first and second EEOF modes for $200-\mathrm{hPa}$ velocity potential form a pair consisting of spatial patterns that display, except for a phase shift, a similar temporal evolution. These two EEOF modes of each analysis describe the evolution of the divergent component of the upper-level flow related to the MJO. The percent of the total intraseasonal variance explained by the first two boreal winter (summer) modes is $56 \%$ $(49 \%)$. For conciseness, we present only the patterns corresponding to the first EEOF mode of each analysis. The patterns for $200-\mathrm{hPa}$ velocity potential, OLR, 500-hPa pressure vertical velocity and SLP are displayed every two time lags. Timelongitude sections have been constructed for 200and $850-\mathrm{hPa}$ zonal winds, $500-\mathrm{hPa}$ geopotential height, $925-\mathrm{hPa}$ temperature, SLP and PW by averaging the correlations between $20^{\circ} \mathrm{N}$ and $20^{\circ} \mathrm{S}$ for each 10 different time lags.

\subsection{Boreal winter (November to March)}

The boreal winter patterns for the $200-\mathrm{hPa}$ velocity potential, OLR, 500-hPa pressure vertical velocity, SLP and 925-hPa specific humidity corresponding to the first EEOF mode are displayed in Figs. 1-5. For all variables the patterns observed for time $t$ and time $t+45 \mathrm{~d}$ (pattern shown only for 925 -hPa specific humidity) are similar, indicating a period of approximately 45 days. The 200-hPa velocity potential (Fig. 1) features a largescale zonal wavenumber one pattern propagating continuously eastward around the globe, with a nearly constant amplitude, as previously shown by Knutson and Weickmann (1987). This pattern exhibits a slight northeast-southwest orientation to the axes of maximum and minimum correlations in the tropics. The tilt toward the east in the northern hemisphere (NH) possibly reflects downstream midlatitude circulation changes that are related to variations in the intensity of tropical convection. Higgins and Mo (1997) documented the relationship between persistent wintertime circulation anomalies over central and eastern North Pacific and tropical convective activity over Indonesia and western equatorial Pacific associated with the MJO. Thus other subtropical and extratropical circulation features, such as moisture bursts and cloud bands from the tropics (McGuirk et al., 1987, 1988; Mo and Kousky, 1993), may also be linked to the MJO and therefore contribute to the observed northeast-southwest tilt.

The patterns for the other variables show a more complex spatial structure. The patterns for OLR (Fig. 2) and 500-hPa pressure vertical velocity (Fig. 3) are quite similar. Areas of reduced (enhanced) convection coincide with areas of sinking (rising) motion at $500-\mathrm{hPa}$, indicated by positive (negative) correlations for OLR and $500-\mathrm{hPa}$ pressure vertical velocity, respectively. For both variables the extreme correlations, throughout the evolution of the patterns, remain in the eastern 


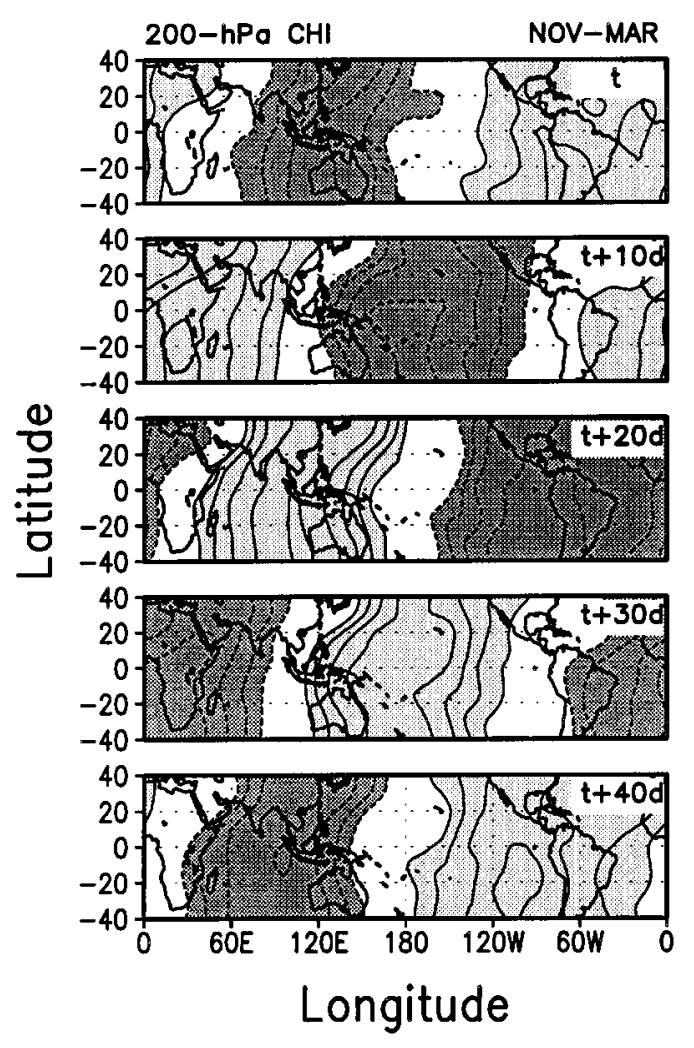

Fig. 1. Boreal winter (November-March) patterns corresponding to the first EEOF mode for filtered (intraseasonal, 30-60 day band) $200-\mathrm{hPa}$ velocity potential anomalies. The values are correlations between the filtered anomaly time series at each grid point and the amplitude time series for the first EEOF mode. Contour interval is 0.15 . Light (dark) shading indicates values greater (less) than $0.3(-0.3)$. Zero line is not shown.

hemisphere, in particular over the Indian Ocean and western Pacific regions. The general feature of these patterns is the eastward progression of the centers of maximum and minimum correlations, which is more uniform in the regions where the values are the largest, consistently with previous works on the MJO (Madden and Julian, 1971, 1972; Weickmann, 1983; Lau and Chan, 1985). Besides the eastward progression, at times, large OLR correlations extend to higher latitudes, especially in the vicinities of the Indian Ocean, Australia and South Pacific Convergence Zone (SPCZ). This feature has been noted by Wang and Rui (1990) and the relationship between MJO activity and variability in the onset and intensity

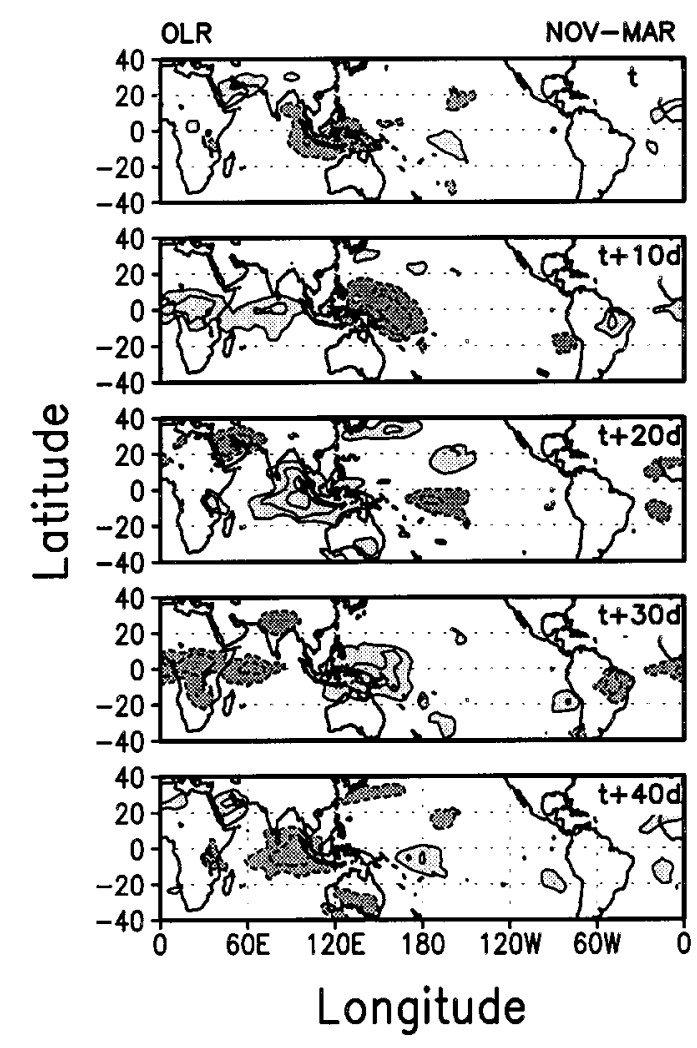

Fig. 2. Same as Fig. 1, except for outgoing longwave radiation (OLR). Contour interval is 0.15 . Light (dark) shading indicates values greater (less) than $0.3(-0.3)$.

of the Australian monsoon has been discussed by Hendon and Liebmann (1990).

The SLP patterns (Fig. 4) show strong symmetry about the equator, and considerable zonal symmetry at certain time lags, a feature evident in the schematic evolution of the MJO given by Madden and Julian (1972) (Fig. 16 therein). The largest correlations are found in the region from the Indian Ocean eastward to South America. In addition to the zonally symmetric (standing) component, there is also an eastward propagating wavenumber one component with a period of approximately 45 days.

The 925-hPa specific humidity pattern shows a regional variability with its largest correlations occurring over equatorial Africa, Saudi Arabia, northern South America, along the SPCZ and over central and eastern Pacific (Fig. 5). For central and eastern Pacific the pattern splits into the 


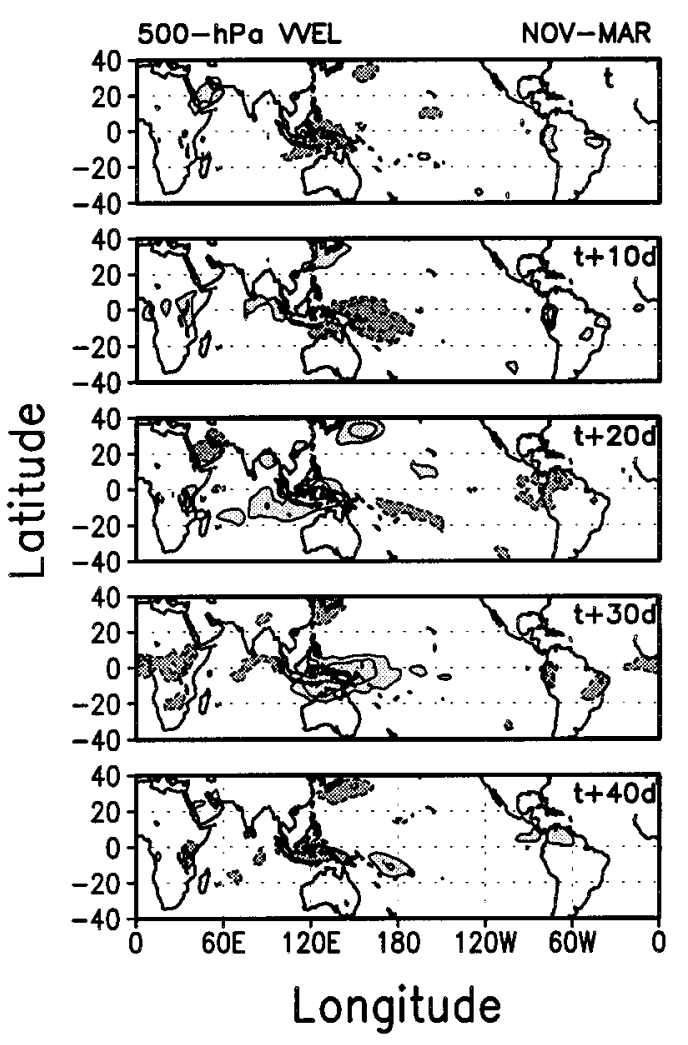

Fig. 3. Same as Fig. 1, except for pressure vertical velocity at $500-\mathrm{hPa}$.

NH and southern hemisphere (SH) parts with the equatorial region dominated by climatologically cold waters without any significant correlations. It seems therefore that the presence of cold waters in equatorial eastern Pacific contributes to weaken the intraseasonal variability of the $925-\mathrm{hPa}$ specific humidity in this region.

The MJO-related evolving aspects of the 925-hPa specific humidity winter patterns are indeed quite complex. Positive correlations in the vicinity of Borneo observed at time $t$, gradually progress southward and eastward, elongating along the SPCZ at time $t+15 \mathrm{~d}$, becoming stronger and extending farther east into southeastern Pacific at time $t+20 \mathrm{~d}$, reaching the subtropical western South American coast at time $t+25 \mathrm{~d}$ where they weaken through the subsequent times. Considerably large positive correlations in central Pacific straddling the equator in the eastern side of this ocean, at time $t+40 \mathrm{~d}$ progress east-

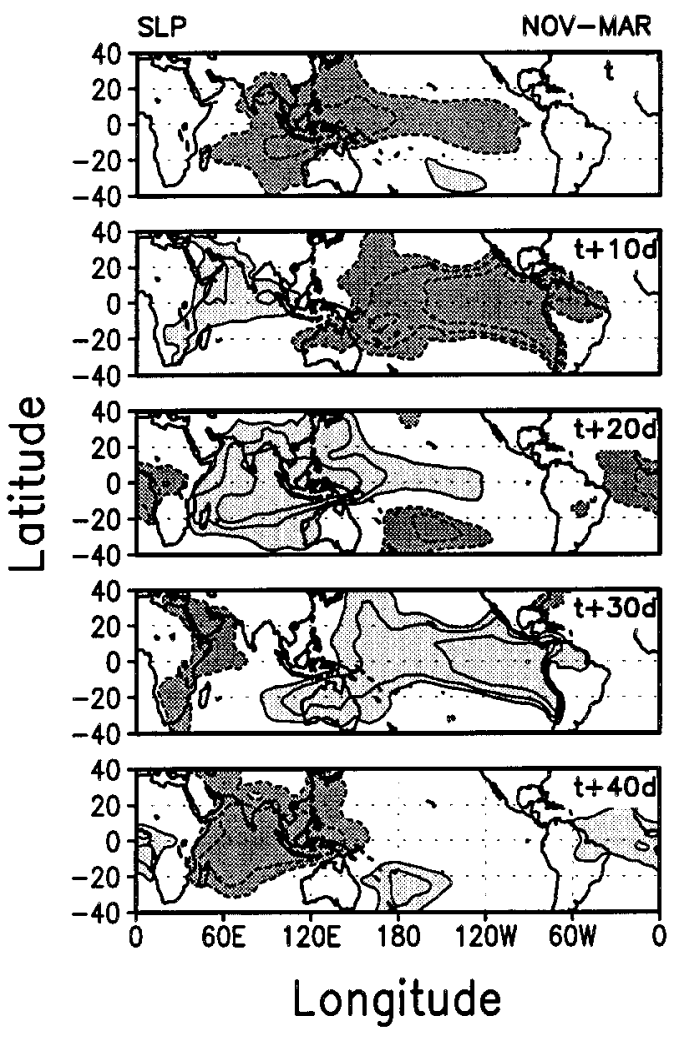

Fig. 4. Same as Fig. 1, except for sea level pressure.

ward quite slowly, becoming stronger at time $t+45 \mathrm{~d}$. Subsequently, the positive correlations weaken and split into $\mathrm{NH}$ and $\mathrm{SH}$ separated parts over eastern Pacific at times $t$ and $t+5 \mathrm{~d}$. Positive correlations are then found over northern South America where they persist through time $t+15 \mathrm{~d}$, then becoming weaker over equatorial Atlantic, extending over equatorial Africa and Saudi Arabia at time $t+20 \mathrm{~d}$ and persisting over these continental areas at times $t+25 \mathrm{~d}$ and $t+30 \mathrm{~d}$. The 925-hPa specific humidity negative correlations feature a similar evolution. In summary, the largest correlations follow two paths, one from Indonesia southeastward along the SPCZ and then eastward in the subtropical latitudes of southeastern Pacific, and the other path eastward near the equator, which is more evident in central and eastern Pacific. Throughout the evolution of the patterns, the largest correlations along these two paths occur almost simultaneously.

Inspections of the time-longitude diagrams 

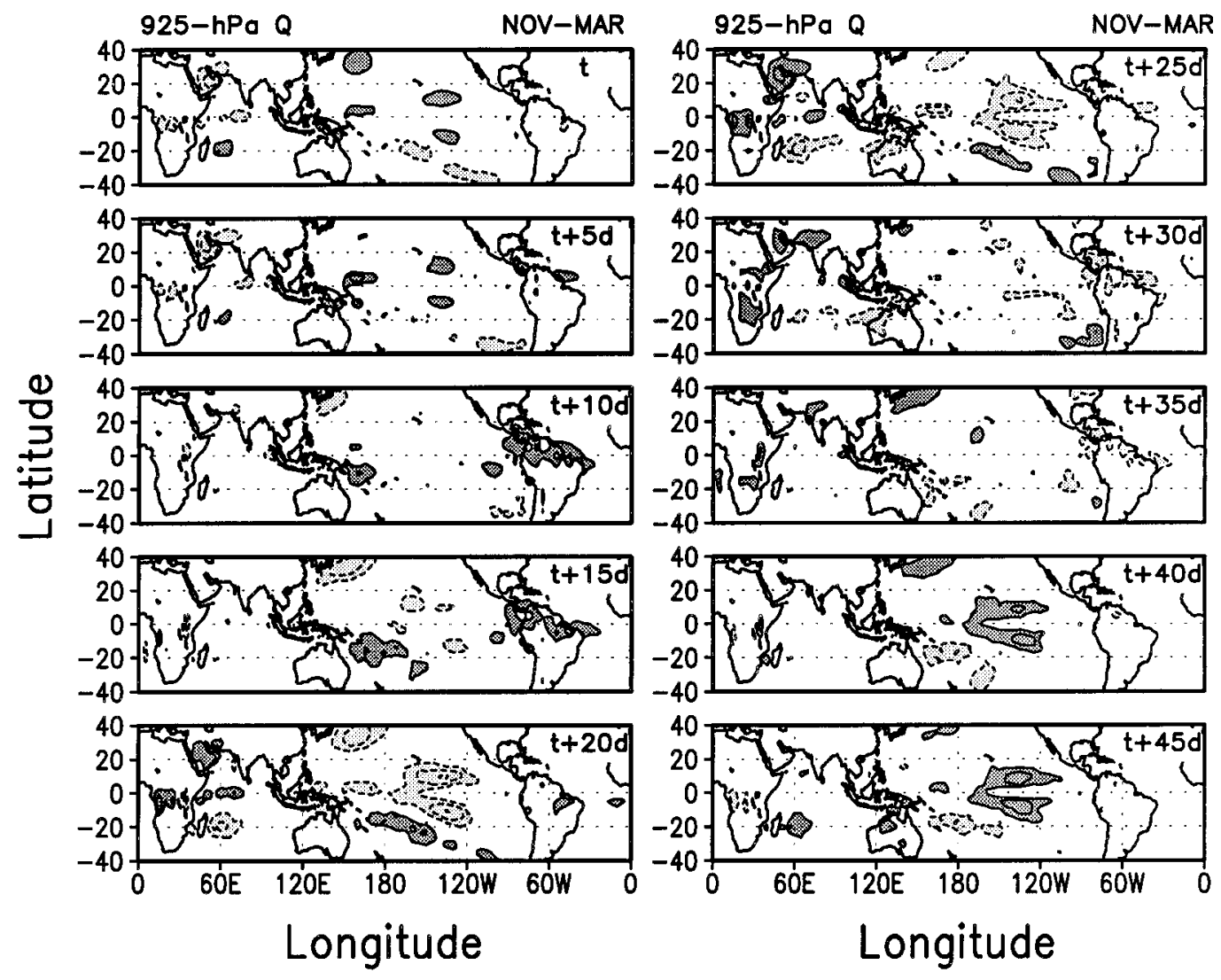

Fig. 5. Same as Fig. 1, except for 925-hPa specific humidity. Light (dark) shading indicates values less (greater) than $-0.3(0.3)$.

show that the 200- and $850-\mathrm{hPa}$ zonal winds, PW and $925-\mathrm{hPa}$ temperature display a well-defined wavenumber one pattern, while the $500-\mathrm{hPa}$ geopotential height and SLP, a nearly standing zonally symmetric component (wavenumber zero pattern), that is more pronounced over the Indian and Pacific Oceans (Fig. 6). The eastward propagation speed of the patterns for some variables, as inferred from the time-longitude diagrams, differs from region to region. In fact, the SLP and PW patterns propagate eastward considerably slower in the eastern hemisphere than in the eastern Pacific. The 850 - and 200-hPa zonal wind patterns show a nearly constant propagation rate, in particular between $60^{\circ} \mathrm{E}$ and $60^{\circ} \mathrm{W}$. For the low-level variables (SLP, PW and 925-hPa temperature), it is also noticeable a sign reversal of the correlations near $80^{\circ} \mathrm{W}$ and near $40^{\circ} \mathrm{E}$, which correspond approximately to the longitudes of the Andes mountains and the high terrain in eastern Africa, respectively. For the other variables, this sign reversal is more evident only for the $500-\mathrm{hPa}$ geopotential height near $80^{\circ} \mathrm{W}$.

The baroclinic structure of the wind in the deep tropics noted in previous works (Krishnamurti and Gadgil, 1985; Weickmann et at., 1985) is confirmed in our analyses. The PW and $925-\mathrm{hPa}$ temperature patterns are in phase with each other and $180^{\circ}$ out-of-phase with the SLP patterns. Further, the areas of negative (positive) $925-\mathrm{hPa}$ temperature correlations are flanked to the west by negative (positive) $850-\mathrm{hPa}$ zonal wind correlations and to the east by positive (negative) $850-\mathrm{hPa}$ zonal wind correlations. Thus, areas with cooler (warmer) air at $925-\mathrm{hPa}$ and reduced (increased) PW are accompanied by SLP higher (lower) than 

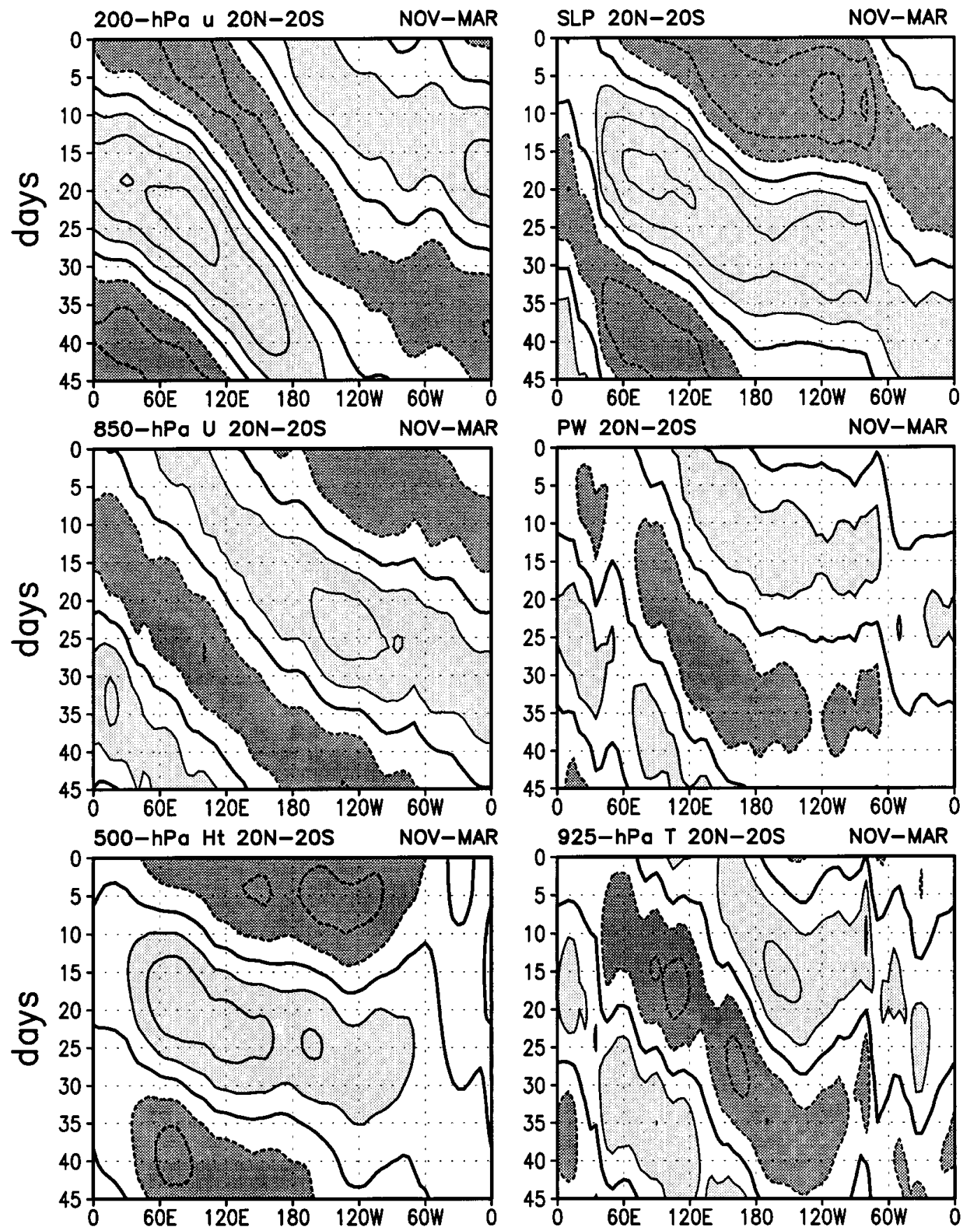

Fig. 6. Longitude-time sections of the average correlation values between $20^{\circ} \mathrm{N}$ and $20^{\circ} \mathrm{S}$ of the correlation patterns corresponding to the first EEOF mode during boreal winter for 200- and $850-\mathrm{hPa}$ zonal wind, $500-\mathrm{hPa}$ geopotential height, SLP, PW and 925-hPa temperature. Contour interval is 0.15 . Dark (light) shading indicates values less (greater) than $-0.3(0.3)$. Zero line is included. 
normal, and, therefore, by enhanced (reduced) low-level divergence. These results are consistent with those obtained by Madden and Julian (1971) for Canton Island who focused on the relationship between tropospheric temperature and station pressure related to the MJO. Consistent with our results, Bantzer and Wallace (1996), in their analysis of the MJO-related variations in temperature and precipitation, showed that as the precipitation intensifies, the tropical troposphere warms.

\subsection{Boreal summer (May to September)}

The boreal summer patterns for $200-\mathrm{hPa}$ velocity potential, OLR, 500-hPa pressure vertical velocity, SLP and $925-\mathrm{hPa}$ specific humidity for the first EEOF mode are displayed in Figs. 7-11. As in the case for austral summer, the patterns describe an oscillation with a period of approximately 45 days. The $200-\mathrm{hPa}$ velocity potential (Fig. 7) displays a zonal wavenumber one pattern propagating continuously eastward around the globe, with a northwest-southeast orientation to the axes of maximum and minimum correlations in the tropics.

The OLR and 500-hPa pressure vertical velocity largest correlations (Figs. 8,9) extend from the Indian Ocean to Central America, crossing the Pacific approximately along the climatological position of the intertropical convergence zone (ITCZ). Similar to winter, the largest correlations occur over the areas experiencing the greatest climatological convection, and the eastward progression of the patterns is more uniform over the Indian and western Pacific Oceans. The relatively large correlations over Central America, indicate the importance of this region in the evolution of the MJO during boreal summer. In the Indian Ocean a combined northward and eastward progression of the correlations is consistent with the well known MJO effects on the Indian summer monsoon (Yasunari, 1979; Sikka and Gadgil, 1980; Yasunari, 1980, 1981; Krishnamurti and Subrahmanyam, 1982; Lau and Chan, 1986).

The SLP patterns (Fig. 10) exhibit a strong symmetry about the equator, and strong zonal symmetry superimposed on a transient eastwardpropagating component having a period of approximately 45 days. The largest correlations extend eastward from the Indian Ocean to South America. Throughout the evolution, the SLP pat-

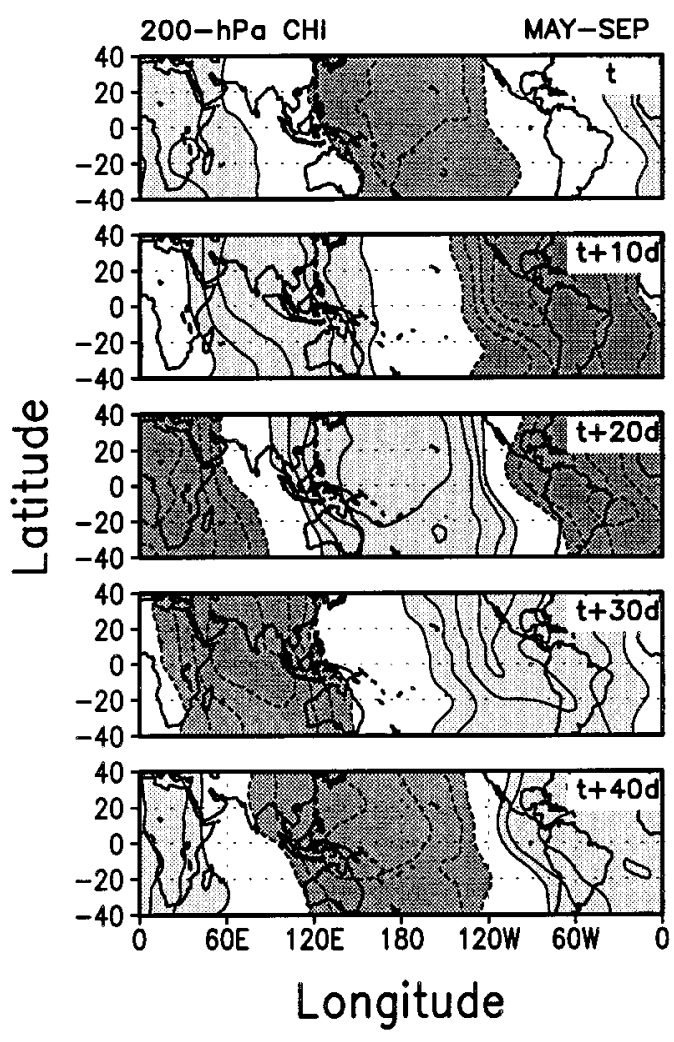

Fig. 7. Boreal summer (May-September) patterns corresponding to the first EEOF mode for filtered (intraseasonal, $30-60$ day band) $200-\mathrm{hPa}$ velocity potential anomalies. Values are correlations between the filtered anomaly time series at each grid point and the amplitude time series for the first EEOF mode. Contour interval is 0.15 . Light (dark) shading indicates values greater (less) than $0.3(-0.3)$. Zero line is not shown.

terns appear to be more confined to the equatorial region $\left(20^{\circ} \mathrm{N}-20^{\circ} \mathrm{S}\right)$ during boreal summer than during austral summer (Fig. 4).

The boreal summer MJO-related $925-\mathrm{hPa}$ specific humidity patterns (Fig. 11) show a $180^{\circ}$ out-of-phase relationship with those for SLP, with the largest positive (negative) correlations occurring in the vicinity of the largest negative (positive) SLP correlations. The $925-\mathrm{hPa}$ specific humidity patterns feature a structure nearly symmetric about the equator and some zonal symmetry at certain time lags. These patterns progress eastward almost continuously with a period of approximately 45 days, and throughout the evolution, the largest correlations remain in the equatorial 


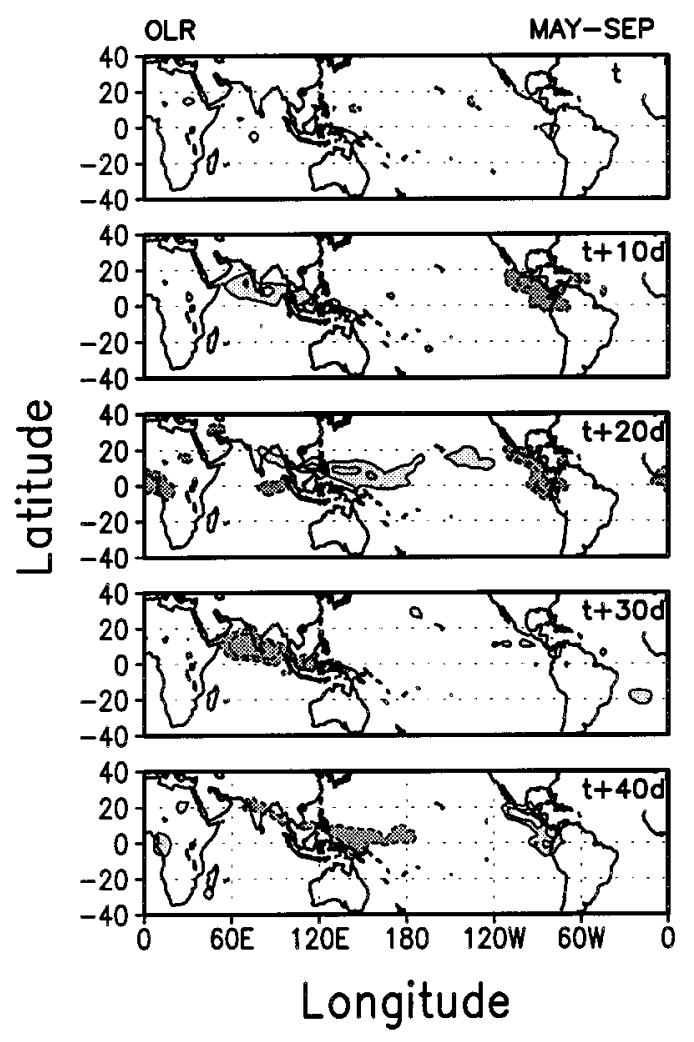

Fig. 8. Same as Fig. 7, except for outgoing longwave radiation (OLR). Contour interval is 0.15 . Light (dark) shading indicates values greater (less) than $0.3(-0.3)$.

Pacific areas. It is evident that these patterns contain a large-scale component, rather than the regional variability noted for boreal winter. It is also interesting to note that maximum (minimum) correlations for the $925-\mathrm{hPa}$ specific humidity occur approximately $90^{\circ}$ to the east of the minimum (maximum) correlations for OLR and 500-hPa pressure vertical velocity.

The boreal summer time-longitude sections (Fig. 12) show a well defined wavenumber one pattern for some variables (850- and 200-hPa zonal winds, $\mathrm{PW}$ and $925-\mathrm{hPa}$ temperature) and a wavenumber zero pattern for others (SLP and $500-\mathrm{hPa}$ geopotential height). As for austral summer, the eastward propagation rate for certain variables shows differences around the globe. The 500-hPa geopotential height and SLP patterns propagate eastward from the Greenwich meridian to $80^{\circ} \mathrm{E}$ at a comparable rate, which is lower for

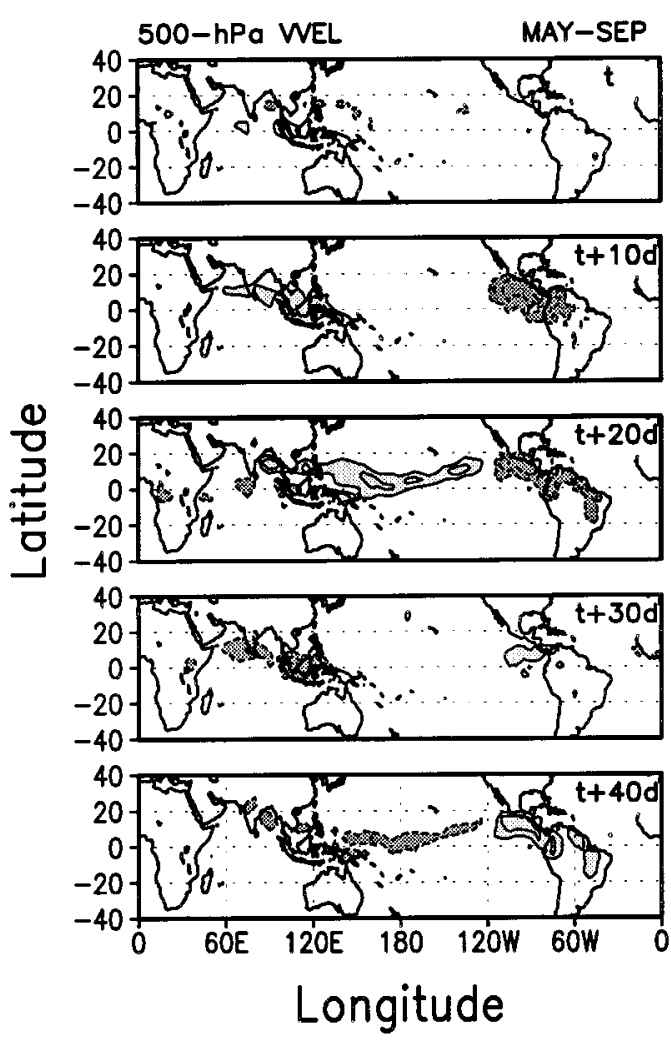

Fig. 9. Same as Fig. 7, except for pressure vertical velocity at $500-\mathrm{hPa}$.

these longitudes than elsewhere. A nearly constant propagation rate is observed for $200-$ and $850-\mathrm{hPa}$ zonal winds and PW. For boreal summer, the sign reversal of the patterns along the longitudes of the Andes Mountains and the relatively high terrain in eastern Africa is evident in the SLP, 925-hPa temperature and $500-\mathrm{hPa}$ geopotential height diagrams. As observed during boreal winter, the zonal wind patterns (Fig. 12) show a baroclinic structure in the equatorial band, consistent with previous results (Krishnamurti and Gadgil, 1985; Weickmann et at., 1985) and the MJO-related variations in $925-\mathrm{hPa}$ temperature, $850-\mathrm{hPa}$ zonal wind, PW and SLP are intimately connected.

\section{Conclusions}

OLR data and several variables derived from the NCEP/NCAR reanalyzed dataset were used 


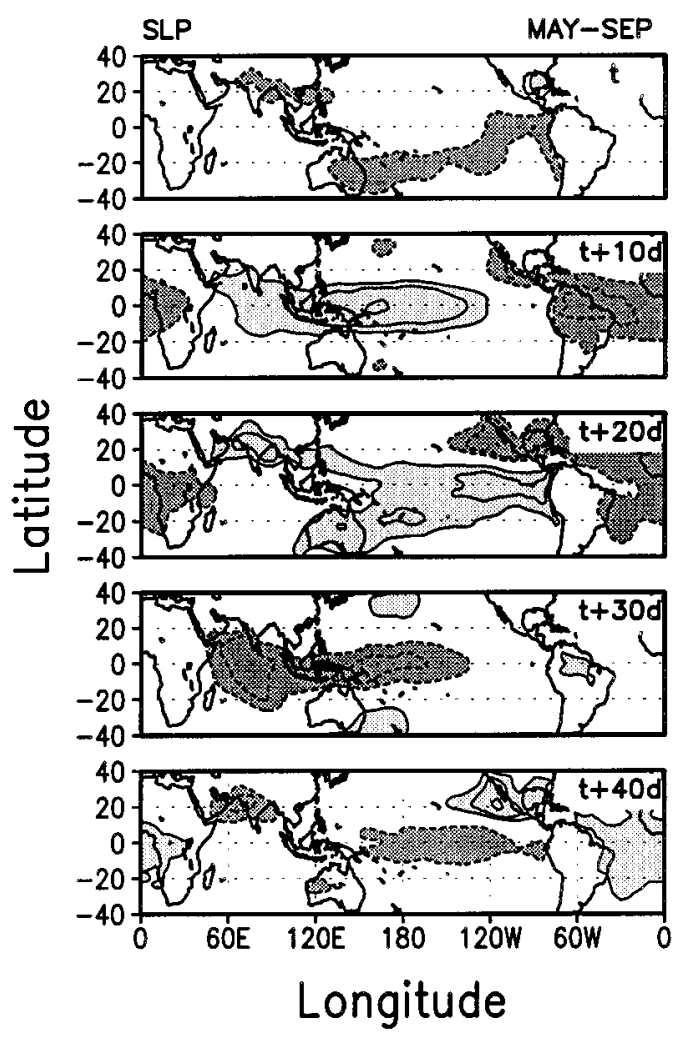

Fig. 10. Same as Fig. 7, except for sea level pressure.

to describe boreal winter and summer MJO features during the 1979-1995 period. The absence of inhomogeneities in the reanalyzed data, due to changes in model physics and resolution, allowed for a comprehensive analysis of several aspects of MJO. Previous studies on the MJO were based on fewer variables and were restricted to a shorter period of record.

Evolving intraseasonal patterns of the variables, determined using EEOF analyses, show that the MJO is characterized by an eastward propagating large-scale zonal wavenumber one pattern, with most variables displaying symmetry about the equator and some variables showing considerable zonal symmetry. The average period of the MJO of approximately 45 days and the circulation features of the oscillation, as shown in $200-\mathrm{hPa}$ velocity potential, $200-\mathrm{hPa}$ and $850-\mathrm{hPa}$ zonal winds, 500-hPa geopotential height and SLP patterns, confirm previous findings on the MJO (Madden and Julian, 1972; Weickmann, 1983;
Anderson et al., 1984; Weickmann et al., 1985; Knutson et al., 1986; Knutson and Weickmann, 1987; Cadet and Daniel, 1988; Kiladis and Weickmann, 1992).

The MJO has the strongest effects in the eastern hemisphere where the OLR correlation patterns show a more uniform eastward and meridional propagation. The boreal winter largest OLR correlations expand southeastward from the Indian Ocean toward Australia, approximately along the path of clouds during active periods of the Australian monsoon (Wang and Rui, 1990). Similar results have also been found by Hendon and Liebmann (1990). On the other hand, the boreal summer OLR correlations progress northeastward in the Indian Ocean, coherently with the northwest-southeast orientation of the main features of the 200-hPa velocity potential correlation patterns. A direct relationship between the northward and eastward progressions of the clouds during the active phase of the Indian summer monsoon has been noted by Yasunari (1979), who suggested that this feature is related to the MJO. After Yasunari (1979), several papers confirmed his results (Sikka and Gadgil, 1980; Yasunari, 1980, 1981; Krishnamurti and Subrahmanyam, 1982; Lau and Chan, 1986). Our results show that the MJO-related anomalous convection over the Indian and western Pacific Oceans depends strongly on the seasonal meridional shifts of the tropical convection over these oceans and indeed confirm that the MJO plays an important role in modulating the Australian and Indian monsoons during the austral and boreal summer seasons, respectively.

For the American sector, Kousky and Kayano (1994) determined the principal OLR and 250-hPa circulation intraseasonal evolving patterns by using data for all seasons. The evolving patterns presented in their Fig. 8 are a combination of summer and winter patterns. The OLR and 500-hPa pressure vertical velocity patterns shown here display relatively large correlations over northeast Brazil during austral summer and over Central America and extreme eastern North Pacific, during boreal summer. Since convection in these areas is in part controlled by the proximity of the ITCZ (Schwerdtfeger, 1976), the latitudinal differences in the locations of the largest OLR correlations from winter to summer in the 

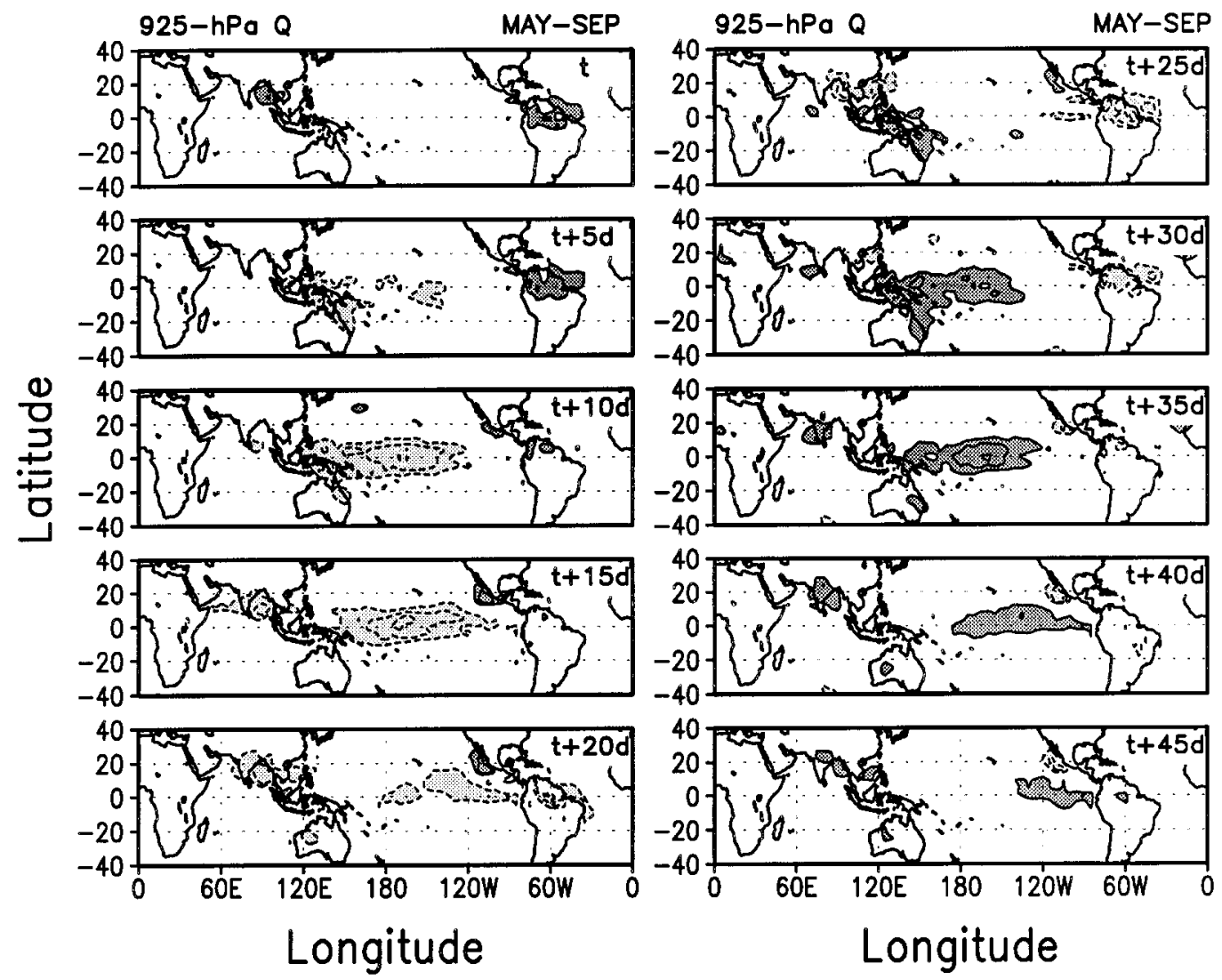

Fig. 11. Same as Fig. 7, except for 925-hPa specific humidity. Light (dark) shading indicates values less (greater) than $-0.3(0.3)$.

Americas seem to depend on the ITCZ's regional seasonal cycle.

The variables with strong zonal symmetry in the MJO-related patterns are dominated by wavenumber one or zero pattern. For the low-level variables these patterns reflect in addition the presence of mountains (Andes and high lands in eastern Africa). Since these variables are extrapolated to pressure levels beneath the Earth's surface, this feature might reflect this fact. Discontinuities of the 500-hPa geopotential height patterns near $80^{\circ} \mathrm{W}$ for boreal winter and near $80^{\circ} \mathrm{W}$ and $40^{\circ} \mathrm{E}$ for boreal summer, suggest however that orographic effects may be important for some variables. In addition, differences in the eastward propagation rate of the MJO depending on the region are evident for SLP. For both seasons, the SLP patterns propagate relatively slow in the eastern hemisphere, where the convection is more active, and faster in the eastern Pacific, where climatologically cold equatorial waters are observed. This suggests that the tropical sea surface temperature (SST) and the convection affect the eastward propagation rate of the MJO.

Furthermore, the MJO-related evolving aspects of the $925-\mathrm{hPa}$ specific humidity so far not discussed are examined here. The MJO-related patterns for this variable show remarkable seasonal dependence. The boreal summer patterns display large-scale features consistent to those for SLP, while those for austral summer show considerable regional variability. The more regional structure of austral summer patterns might indicate the interactions of the MJO with regional convection, such as along the SPCZ and in the northern South America. However, the absence of significant cor- 

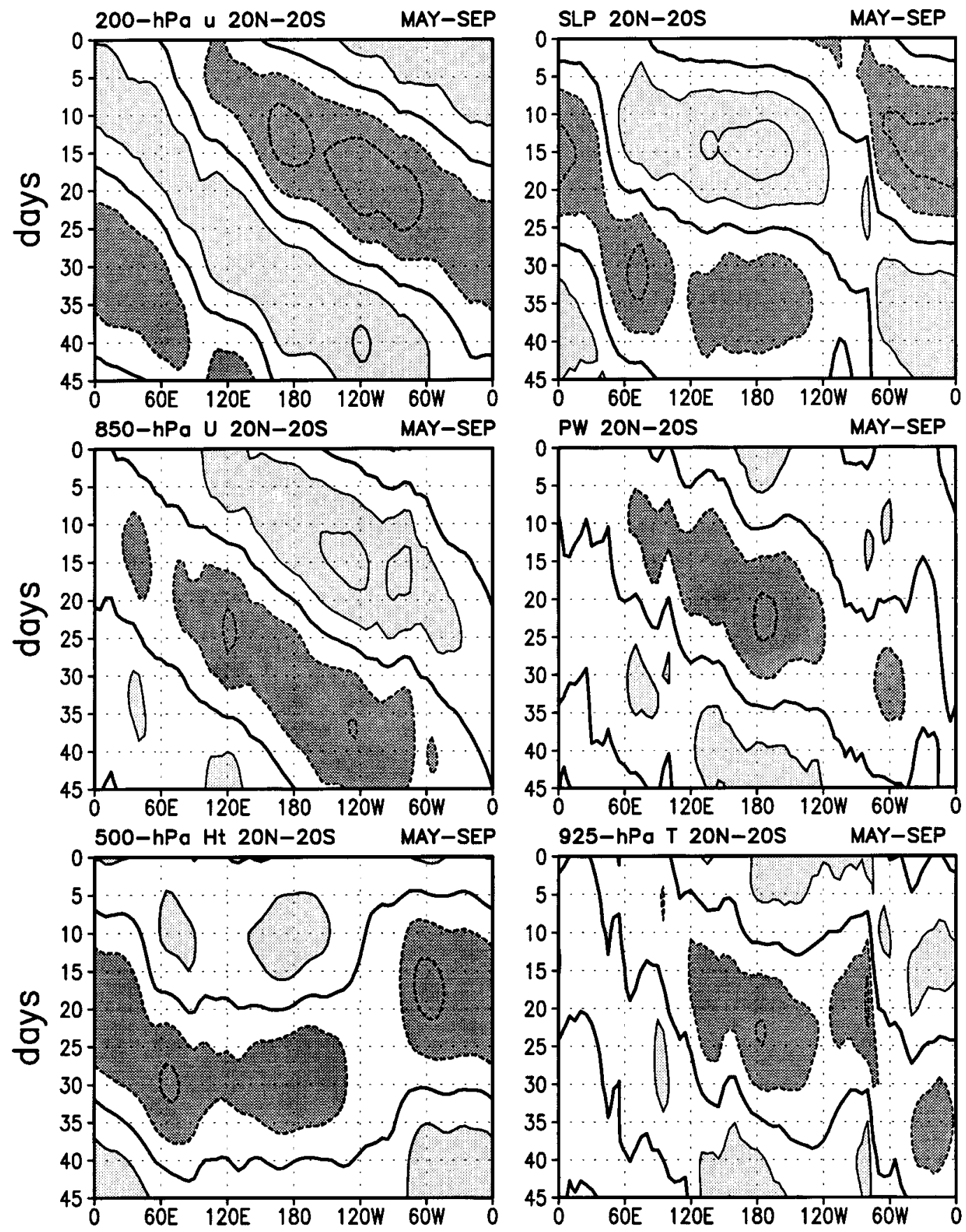

Fig. 12. Longitude-time sections of the average correlation values between $20^{\circ} \mathrm{N}$ and $20^{\circ} \mathrm{S}$ of the correlation patterns corresponding to the first EEOF mode during boreal summer for 200- and 850-hPa zonal wind, 500-hPa geopotential height, SLP, PW and 925-hPa temperature. Contour interval is 0.15 . Dark (light) shading indicates values less (greater) than $-0.3(0.3)$. Zero line has been included. 
relations over Indonesia, where the MJO-related signals in the OLR are quite strong during boreal winter, is intriguing and needs further analyses. For boreal summer, the largest positive (negative) 925-hPa specific humidity correlations in a given area lead by approximately 10 days the largest negative (positive) OLR correlations, suggesting enhanced low-level moisture convergence (divergence) prior to periods of greater (weaker) than normal convection. This result seems to be useful for climate monitoring and certainly have important implications for modeling studies.

Some results presented here should be taken with care. The 925-hPa specific humidity has been classified in category B for the NCEP reanalysis (Kalnay et al., 1996), meaning that there are observational data that directly affect the value of the variable, but the model has a strong influence on the variable value. Since observations over oceanic areas are rare, special care should be taken for the patterns over these areas. However, the physical consistency between the $925-\mathrm{hPa}$ specific humidity and SLP patterns for boreal summer provides an indication of the reliability of the 925-hPa specific humidity data.

The above analyses provide a general view of the MJO-related variability in the tropics and several aspects of this oscillation were clearly illustrated using reanalyzed data. All these observed circulation and OLR features are fairly consistent with the theoretical results regarding the atmospheric response to a tropical heat source as a coupled Kelvin-Rossby wave. Both theoretical and simulation studies indicate that convective forcing near the equator excites Rossby and Kelvin waves out of the forcing region (Gill, 1980; Goswami and Shukla, 1984). Accordingly, for both seasons the $200-\mathrm{hPa}$ streamfunction patterns (figures not shown) display an anticyclonic circulation couplet straddling the equator to the west of the enhanced convection region; the low-level circulation patterns feature westerlies (easterlies) to the west (east) of this region, and the SLP patterns show negative anomalies symmetric about the equator over the enhanced convection region.

The authors think that the major contribution of this paper to the MJO modeling studies comes from the results of the $925-\mathrm{hPa}$ specific humidity analyses. Most of the theoretical and modeling studies dealing with the MJO agree that the moist processes play an important role in the oscillation. Nevertheless, others aspects of the MJO-related variations for the specific humidity should be further investigated.

\section{Acknowledgements}

The authors thank the two anonymous reviewers for their helpful comments and suggestions. The first author was partially supported by Conselho Nacional de Desenvolvimento Científico e Tecnológico under grant number 300033/94-0.

\section{REFERENCES}

Anderson, J. R. and Rosen, R. D. 1983. The latitudeheight structure of 40-50 day variations in atmospheric angular momentum. J. Atmos. Sci. 40, 1584-1591.

Anderson, J. R. and Stevens, D. E. 1987. The presence of linear wavelike modes in a zonally symmetric mode of the tropical atmosphere. J. Atmos. Sci. 44, 2115-2127.

Anderson, J. R., Stevens, D. E. and Julian, P. R. 1984 Temporal variations of the tropical 40-50 day oscillation. Mon. Wea. Rev. 112, 2431-2438.

Bantzer C. H. and Wallace, J. M. 1996. Intraseasonal variability in tropical mean temperature and precipitation and their relation to the tropical 40-50 day oscillation. J. Atmos. Sci. 53, 3032-3044.

Cadet, D. L. and Daniel, P. 1988. Long-range forecast of the break and active summer monsoons. Tellus 40A, 133-150.
Duchon, C. E. 1979. Lanczos filtering in one and two dimensions. J. Appl. Meteor. 18, 1016-1022.

Ghil, M. and Mo, K. C. 1991. Intraseasonal oscillations in the global atmosphere. Part I: Northern Hemisphere and tropics. J. Atmos. Sci. 48, 752-779.

Gill, A. E. 1980. Some simple solutions for heat-induced tropical circulation. Quart. J. Roy. Meteor. Soc. 106, 447-463.

Goswami, B. N. and Shukla, J. 1984. Quasi-periodic oscillation in a symmetric general circulation model. J. Atmos. Sci. 42, 20-37.

Gruber, A. and Krueger, A. F. 1984. The status of the NOAA outgoing longwave radiation data set. Bull. Amer. Meteor. Soc. 65, 958-962.

Hendon, H. H. and Liebmann, B. 1990. A composite study of onset of the Australian summer monsoon. J. Atmos. Sci. 47, 2227-2240.

Tellus 51A (1999), 3 
Higgins, R. W. and Mo, K. C. 1997. Persistent North Pacific circulation anomalies and the tropical intraseasonal oscillation. J. Climate 10, 223-244.

Kalnay, E. and coauthors, 1996. The NCEP/NCAR 40-year reanalysis project. Bull. Amer. Meteor. Soc. 77, 437-471.

Kiladis, G. N. and Weickmann, K. M. 1992. Circulation anomalies associated with tropical convection during Northern winter. Mon. Wea. Rev. 120, 1900-1923.

Knutson, T. R. and Weickmann, K. M. 1987. 30-60 day atmospheric oscillations: Composite life cycles of convection and circulation anomalies. Mon. Wea. Rev. 115, 1407-1436.

Knutson, T. R., Weickmann, K. M. and Kutzbach, J. E. 1986. Global-scale intraseasonal oscillation of out going longwave radiation and $250-\mathrm{mb}$ zonal wind during northern hemisphere summer. Mon. Wea. Rev. 114, 605-623.

Kousky, V. E. and Kayano, M. T. 1993. Real-time monitoring of intraseasonal oscillations. Proceedings of the 18th Annual Climate Diagnostics Workshop, 1-5 November 1993, Boulder, CO, 66-69.

Kousky, V. E. and Kayano, M. T. 1994. Principal modes of outgoing longwave radiation and $250-\mathrm{mb}$ circulation for the South American sector. J. Climate 7, 1131-1143.

Krishnamurti, T. N. and Subrahmanyam, D. 1982. The 30-50 day mode at $850 \mathrm{mb}$ during MONEX. J. Atmos. Sci. 39, 2088-2095.

Krishnamurti, T. N. and Gadgil, S. 1985. On the structure of the 30 to 50 day mode over the globe during FGGE, Tellus 37A, 336-360.

Langley, R. B., King, R. W., Shapiro, I. I., Rosen, R. D. and Salstein, D. A. 1981. Atmospheric angular momentum and the length of day: a common fluctuation with a period near 50 days. Nature 294, 730-732

Lau, K.-M. and Chan, P. H. 1985. Aspects of the 40-50 day oscillation during the Northern winter as inferred from outgoing longwave radiation. Mon. Wea. Rev. 113, 1889-1909.

Lau, K.-M. and Chan, P. H. 1986. Aspects of the 40-50 days oscillation during the northern summer as inferred from outgoing longwave radiation. Mon. Wea. Rev. 114, 1354-1367.

Madden, R. A. 1986. Seasonal variations of the 40-50 day oscillation in the tropics. J. Atmos. Sci. 43, 3138-3158.

Madden, R. A. 1987. Relationship between changes in the length of day and the 40 to 50 day oscillation in the tropics. J. Geophys. Res. 92, 8391-8399.

Madden, R. A. and Julian, P. R. 1971. Detection of a 40-50 day oscillation in the zonal wind in the tropical Pacific. J. Atmos. Sci. 28, 702-708.

Madden, R. A. and Julian, P. R. 1972. Description of global-scale circulation cells in the tropics with a 40-50 day period. J. Atmos. Sci. 29, 1109-1123.

Madden, R. A. and Julian, P. R. 1994. Observations of the 40-50 day tropical oscillation - A review. Mon Wea. Rev. 122, 814-837.
McGuirk, J. P., Thompson, A. H. and Smith, N. R. 1987. Moisture burst over the tropical Pacific Ocean. Mon. Wea. Rev. 115, 787-798.

McGuirk, J. P., Thompson, A. H. and Schaffer, J. R. 1988. An eastern Pacific tropical plume. Mon. Wea. Rev. 116, 2505-2521.

Mo, K. C. and Kousky, V. E. 1993. Further analysis of the relationship between circulation anomaly patterns and tropical convection. J. Geophys. Res. 98, 5103-5113.

Rasmusson E. M. and Arkin, P. A. 1985. Interannual climate variability associated with the El Niño/Southern Oscillation. Coupled ocean-atmosphere models, J. C. Nihoul, ed., Elsevier, pp. 289-302.

Rosen, R. D. and Salstein, D. A. 1983. Variations in atmospheric angular momentum on global and regional scales and the length of day. J. Geophys. Res. 88, 5451-5470.

Schwerdtfeger, W. 1976. Climates of Central and South America. In: World survey of climatology. Elsevier Scientific Publishing Company, Amsterdam, vol. 12.

Sikka, D. R. and Gadgil, S. 1980. On the maximum cloud zone and ITCZ over Indian longitudes during the southwest monsoon. Mon. Wea. Rev. 108, 1840-1853.

Wallace, J. M., Smith, C. and Jiang, Q. 1990. Spatial patterns of atmosphere-ocean interaction in the northern winter. J. Climate 3, 990-998.

Wang, B. and Rui, H. 1990. Synoptic climatology of transient tropical intraseasonal convection anomalies. Meteor. Atmos. Phys. 44, 43-61.

Weare, B. C. and Nasstrom, J. S. 1982. Example of extended orthogonal function analysis. Mon. Wea. Rev. 110, 481-485.

Weickmann, K. M. 1983. Intraseasonal circulation and outgoing longwave radiation modes during the Northern hemisphere winter. Mon. Wea. Rev. 111, 1838-1858.

Weickmann, K. M., Lussky, G. R. and Kutzbach, J. E. 1985. A global-scale analysis of intraseasonal fluctuations of outgoing longwave radiation and $250 \mathrm{mb}$ streamfunction during northern winter. Mon. Wea. Rev. 113, 941-961.

Yasunari, T. 1979. Cloudiness fluctuations associated with the Northern Hemisphere summer monsoon. J. Meteor. Soc. Japan 57, 227-242.

Yasunari, T. 1980. A quasi-stationary appearance of the 30-40 day period in the cloudiness fluctuations during the summer monsoon over India. J. Meteor. Soc. Japan 58, 225-229.

Yasunari, T. 1981. Structure of an Indian summer monsoon system with around 40-day period. J. Meteor. Soc. Japan 59, 336-354.

Zhang C. and Hendon, H. H. 1997. Propagating and standing components of the intraseasonal oscillation in tropical convection. J. Atmos. Sci. 54, 741-752. 